\title{
Discussion of the Hamermesh Paper
}

\author{
FREDRIC RAINES
}

Daniel Hamermesh has undertaken an extensive survey of what we know about the impact of income maintenance programs on employment, unemployment and labor force participation. Reflected in this paper is an awesome amount of research, both that of others and his own. And, on balance, he has done an excellent job of synthesizing this literature. He is, certainly, the resident expert in this area among us. If this conference is a supplyside harvest, we may note that Hamermesh has been busy tilling the fields, and gathering the crops.

However, there are problems. The first problem Hamermesh has is where to look for evidence of supply side effects. He starts by looking at macro time series data, regressing $\log \frac{\mathrm{U}^{*}}{100-\mathrm{U}^{*}}$ (where $\mathrm{U}^{*}$

is the unemployment rate adjusted for shifts in demographic composition) on lagged values of two policy variables:

(1) NRR - net replacement rate of aggregate transfers payments:

(2) TAX - the overall tax rate on earnings.

Unfortunately the results seem not to be to his liking, though they would warm the heart of a Lafferite. A one standard deviation increase in NRR from its mean raises $U^{*}$ from $5 \%$ to $7.85 \%$, and a similar increase in tax raises $U^{*}$ from $5 \%$ to $6.19 \%$.

Hamermesh then decides that truth may only be revealed by an examination of the effect of individual programs. But not everybody's examination. For instance, the 1973 study of benefits by Feldstein, which finds that Unemployment Insurance benefits and taxes have raised NAIRU by 1.25 percentage points, and a 1977 study by Clarkson and Meiners, which finds that AFDC (Aid to Families with Dependent Children) plus Food Stamps have raised the measured unemployment rate by 2 percentage points, are rejected as patently too large.

Finally Hamermesh hits upon a solution. He takes the Perloff and Wachter (1979) finding that NAIRU has increased since the 
mid 1950 s by about 2 percentage points (of which slightly less than 1 percentage point is due to demographic shifts), and sees if, by an examination of individual programs, he can work up to that modest total. He also investigates what appear to be the more important effects of income maintenance programs - those on employment.

A point about what it is we are trying to measure the effect on is in order here. Hamermesh makes it quite clear that a given program may have distinctly different effects on employment and unemployment. But the unemployment concept that he chooses, and the one commonly used in these studies-NAIRU - is, I would argue, incorrect.

NAIRU refers to that rate of unemployment associated with balance in the product market. But the relevant concept for labor market studies is that unemployment rate which is consistent with a balanced-the number of job vacancies equal to the number of unemployed workers, say-labor market. Unless you are sufficiently neo-classical to deny or ignore differing adjustment speeds, these two concepts need not yield the same number. Indeed, if I define the latter concept as a "full employment" benchmark adjusted over time for demographic shifts-call it the natural rate of unemployment (NRU) - then I can cite the above Perloff and Wachter study as giving evidence that NRU and NAIRU have been diverging over time. But the point is that NAIRU might be consistent with a 5 percent unemployment rate at one point in time, and an 8 percent rate at another, without there being any implication or deducible inference for the impact of supply-side programs on unemployment.

Putting this consideration aside, what does Hamermesh find? Examining research on four different programs: Unemployment Insurance (UI), Social Security, Disability Insurance (DI), and Aid to Families with Dependent Children plus Food Stamps (AFDC/FS), the consensus he finds is that the employment effects (and labor force participation effects) are negative in each case. However, the unemployment effects are mixed, implying reductions in NAIRU for Social Security and DI, and increases in NAIRU for UI and AFDC/FS. For the overall net effect on NAIRU of these programs, Hamermesh likes the number "zero."

It should be pointed out that Hamermesh gets his reductions in NAIRU entirely through changes in the composition of the labor force. Those induced to leave the labor force due to the benefit structure of Social Security and DI, for instance, are assumed to be those with below average marketable skills and above average 
unemployment rates. This is a testable proposition, and while Hamermesh does present some evidence, the full implications do not appear to have been explored. One implication is that average worker productivity should have been increasing as a result of these programs. If so, it was much more than wiped out by other factors. Another implication, which does seem borne out by overall participation data, is that the composition of the labor force is tilted toward younger workers.

One may ask, is the Hamermesh approach of counting the trees to measure the forest a reasonable one? I strongly agree with him that the foundations of imputing a supply-side effect must come from observing micro behavior. There are just too many complexities that get washed out in aggregate data - and our policy proposals must deal with these complexities. At the same time, the effect of these individual programs may not be additive as Hamermesh is inclined to assume. For example, Hamermesh concludes that the net effect of AFDC/FS on labor force participation, employment, and NAIRU is slight. This conclusion is based in part on the gradual reduction in the AFDC implicit tax rate over time. But the AFDC implicit tax rate compounds with the food stamp implicit tax rate, and these compound with the implicit tax rate for Medicaid, Housing Assistance, Child Nutrition, and a few other programs. This is known as the "stacking" problem, and it implies overall effective tax rates in many cases in excess of 100 percent with numerous notches and kinks. If a 100 percent tax rate doesn't have any effect on labor supply then Laffer is really barking up the wrong tree.

I have a final comment to make on "where to look" for supplyside effects. I think that, methodologically, we may want to examine the trees, but conceptually we should be thinking about the forest. The subsidies and implicit taxes of welfare programs, the tax system, and the pattern of government spending are imbedded in our institutions and our culture. I don't know what it means to say that if you abolish UI, the unemployment rate will decline by 3 percentage points. What is being held constant and what is changed? There are important trends to be explained-slow economic growth, virtually stagnant productivity, chronic inflation, dramatic shifts in labor force composition-and the causes may be bigger (or at least more subtle) than our independent variables.

But the tax/transfer system, in toto, does make a difference: consider the following data on income distribution prepared by Watts \& Skidmore (1977): 


\section{INCOME SHARES OF HOUSEHOLDS}

\begin{tabular}{lcc} 
& $\begin{array}{c}\text { Before Taxes } \\
\text { and All Transfers }\end{array}$ & $\begin{array}{c}\text { after Taxes } \\
\text { and Transfers }\end{array}$ \\
\cline { 2 - 3 } lowest 40 percent & $7.5 \%$ & $17.8 \%$ \\
highest 40 percent & $76.2 \%$ & $64.7 \%$
\end{tabular}

aPrograms include insured cash transfers, cash assistance, in-kind transfers, and income and payroll taxes.

One way of looking at these numbers is to say that government programs currently move one third of the way toward instituting a completely egalitarian income distribution. I have no idea what a redistribution of this order of magnitude-and the policies that brought it about-entails for the economic behavior of individuals. But I would venture the guess that those seriously concerned about supply-side economics have bought themselves a rather large and complex research agenda. 


\section{REFERENCES}

Perloff, Jeffrey and Michael Wachter. "A Production-

Nonaccelerating Inflation Approach to Potential Output: Is

Measured Potential Too High." In Karl Brunner and Allan

Meltzer, eds., Three Aspects of Policymaking. Amsterdam:

North Holland, 1979.

Watts, Harold and Felicity Skidmore. "An Update of the Poverty

Picture Plus a New Look at Relative Tax Burdens." Focus,

Institute for Research on Poverty Newsletter, Fall 1977. 